\title{
HEAT TRANSFER MODELLING IN A CIRCULATING FLUIDISED BED BIOMASS BOILER
}

\author{
Alexandre Aibéo, Carlos Pinho \\ Instituto de Engenharia Mecânica e Gestão Industrial (INEGI) \\ Rua do Barroco, 174-214 \\ 4465-519 Leça do Balio, Portugal
}

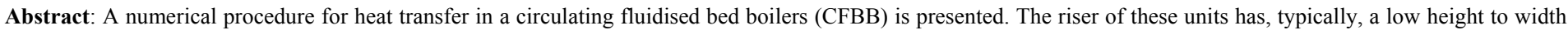
ratio, of order of ten, and low net solids flux. Refractory walls involve the bottom bed and two membrane walls are use to confine a square cross-section conduct that

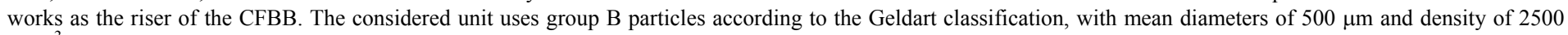
$\mathrm{kg} / \mathrm{m}^{3}$.

The present work is part of a combined effort to develop a complete numerical package to be used in the design of CFB boilers. It only concerns the different features of the heat transfer in CFBB, namely heat transfer coefficients, temperature profiles, its dependencies on fluid dynamic and combustion models, and the calculation of the total thermal power output. The fluid dynamic and combustion models were developed by other teams.

Fluidised bed heat transfer occurs essentially by two mechanisms: convection and radiation and despite showing a complex coupling, they are usually assumed as additive. A CFBB is a complex system, constituted by three main parts: the riser, where the combustion occurs and the particles are fluidised and transported; the cyclone, with the purpose of separating the particles from the gas flow and the downcomer, providing the recirculation of the material back to the riser. The present work concerns

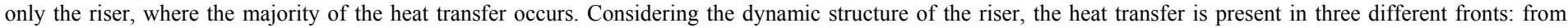

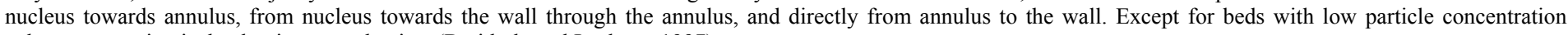
values, convection is the dominant mechanism (Breitholz and Leckner, 1997).

The numerical procedure is applied in layers of infinitesimal height, in order to be possible to solve the energy, the momentum and the continuity equations, and an irregular mesh was used. The bubbling portion of the bed and the splash zone are composed, each one, by a single layer; this approach is a function of the hydrodynamic model upon which the heat transfer model is based. For the core-annulus zone, two columns of infinitesimal layers were used. In fact several meshes are used, concerning fluid-dynamic properties, heat transfer properties and geometrical features.

Key words: Circulating Fluidised Bed Boilers; Heat Transfer; Numerical Modelling, Biomass.
\end{abstract}

Introduction: One of the most efficient ways of taking profit from the fluidization technology is to operate it as a circulating configuration, a closed circuit where the advantages of the high speed fluidization may be fully used. It is usually composed by three main parts: the riser used as a chemical reactor or a boiler; the cyclone to separate particles from gas flow, and the downcomer which closes the circuit. The studied unit is a large circulating fluidised bed boiler (CFBB) working at atmospheric pressure and burning biomass. Its riser has a low height to width ratio, of order of ten, and low net solids flux. Refractory walls involve the bottom bed and two membrane walls confine a square or rectangular crosssection. The considered unit uses group B solids in the Geldart classification, with mean diameters of $500 \mu \mathrm{m}$ and density of 2500 $\mathrm{kg} / \mathrm{m}^{3}$.

Despite a very large list of applications for this kind of technology (Berruti et al., 1995), present attention is centred on biomass burning for heating purposes. The riser of the unit is surrounded by membrane walls where liquid water flows. The heat transfer towards the tubes provides also the way to control the combustion temperature to restrict pollutant emissions. Higher temperature combustion gives rise to higher nitrogen monoxide emissions and alkali metals formation. On the other side, low temperature combustion originates high carbon dioxide and nitrogen dioxide releases (Lyngflet et al., 1998 - reffered in Breithotlz, 2000). Thus, it is of major importance the suitable temperature control, and therefore the fully understanding of the heat transfer phenomena (Breitholtz, 2000).

The major amount of experimental results concerning the heat transfer in CFBB is referred to small scale, laboratorial, installations hardly exceeding $20 \mathrm{~cm}$ in diameter. Although experimental results from a large number of researchers are coherent with each other, they fail when compared with large scale, industrial units. The heat transfer as a function of particle concentration near the walls is dependent of the boiler radius, as a core-annulus structure is expected (Zhang et al., 1995), therefore the small scale results are not useful. Thus, it is fundamental that industrial CFBB are studied, by experimental or numerical modelling means, once building large units for experimental purposes becomes expensive.

In most engineering uses, a model must be simple and pragmatic and still able to provide a complete and concise description of the system to be studied. The model presented herein uses macroscopic properties to describe the system as a whole. As a numerical procedure is necessary, factors like short calculation time and algorithm extension where very important when describing and solving the equations that rule the phenomena. From the numerical point of view, the algorithm was built to follow the hydrodynamic features and only afterwards the heat transfer model was imposed. The resolution of the fundamental equations of continuity, momentum and energy is made after a discretization of the system. Several meshes were used to describe properties of each layer and respective inputs and outputs. Some of

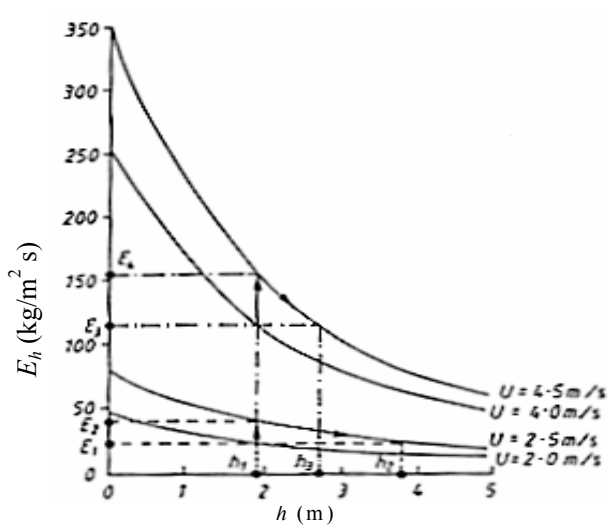
the meshes are not coincident. Following the main characteristics of the hydrodynamic behaviour, the meshes have also a core-annulus structure. However, for the bottom bed and the splash zone, single cells were used.

Figure 1: Particle flux dependence with height for different values of superficial velocity. Rhodes (1989).

Previous Work: Several approaches were proposed by different authors, for the hydrodynamic description of the circulating fluidized bed, although the more accepted one uses a core-annulus structure initially proposed by Rhodes and Geldart (1987) and developed by Bolton and Davidson (1998). Horio et al. (1988) showed that such a model would be complete only if the clusters contribution was accounted for.

The axial hydrodynamic behaviour of a gas/solid flow was first described by Rhodes and Geldart (1987 and 1989), and later developed by Rhodes (1989). The main purpose of their work was to describe the solids distribution and the headloss in the axial direction for the riser. Wen and Chen (1992) proposed the following exponential relation for the particles mass flux 


$$
E_{h}=E_{\infty}+\left(E_{0}-E_{\infty}\right) e^{-a h}
$$

where $E_{h}$ represents the particles mass flux at a given height $h$, above the interface bottom bed/splash zone, $E_{\infty}$ is the particles mass flux at the transport disengaging height (TDH). $E_{0}$ is the flux at the interface (for $h=0$ ) and $a$, a decaying constant. Figure 1 shows the referred behaviour.

The correlations between fluxes and the system properties are again due to Wen and Chen (1982):

$$
E_{\infty}=\rho_{p}\left(1-\varepsilon_{e}\right)\left(U_{0}-V_{T}\right)
$$

$\left(U_{0^{-}} V_{T}\right)$ is the particle velocity at the TDH, where they fall with a treminal velocity $V_{T}$ in a upward flow of superficial velocity $U_{0}$. For the voidage $\varepsilon_{e}$, (Wen and Chen, 1982) proposed the following relationship:

$$
\varepsilon_{e}=\left(1+\frac{\lambda\left(U_{0}-V_{t}\right)^{2}}{2 g D}\right)^{-1 / 4,7}
$$

with $\lambda$, a dimensionless parameter given by:

$$
\lambda= \begin{cases}5,17 \operatorname{Re}^{-1,5} D^{2} d_{p}^{2}\left(\frac{\mu_{g}}{\rho_{g}}\right)^{-2,5} \frac{1}{\rho_{p}}, & R e \leq R e_{c} \\ 12,3 \operatorname{Re}^{-2,5} D d_{p}^{2}\left(\frac{\mu_{g}}{\rho_{g}}\right)^{-2,5} \frac{1}{\rho_{p}}, & R e>R e_{c}\end{cases}
$$

$R e$ is the Reynolds number and $R e_{c}$ is the critical Reynolds number, given by (Wen and Chen, 1982):

$$
\begin{aligned}
& \operatorname{Re}_{c}=\frac{2,38}{D} \\
& \operatorname{Re}=\frac{\rho_{\mathrm{g}}\left(U_{0}-V_{T}\right) d_{p}}{\mu_{g}}
\end{aligned}
$$

For $E_{0}$, the same authors propose a bubble mean diameter dependence, as it follows:

$$
E_{0}=\frac{A d_{b} 3,07 * 10^{-9} \rho_{g}^{3,5} g\left(U_{0}-U_{m f}\right)^{2,5}}{\mu_{g}^{2,5}}
$$

where $d_{b}$ is the mean bubble diameter (taken from Darton et al. (1977) for the top of the bubbling bed) and $U_{m f}$ stands for the minimum fluidization velocity and it is determined by Bayens equation as is recommended by Geldart and Abrahamsen (1981). By continuity, the mass flow must be the same at the exit of the duct, thus for a given bubbling bed height $h_{l b}$, it comes:

$$
G=E_{\infty}+\left(E_{0}-E_{\infty}\right) e^{-a\left(L-h_{l b}\right)}
$$

In order to relate the minimum fluidization velocity without imposed solids flux, $U_{m f}$ with that corresponding to a given solids flux $U_{m f}^{\prime}$, Rhodes (1989), presents a relation that neglects the effects of friction between particles and walls.

$$
\frac{U_{m f}}{\varepsilon_{e, m f}}=\frac{U_{m f}^{\prime}}{\varepsilon_{e, m f}}-\frac{G}{\rho_{p}\left(1-\varepsilon_{e, m f}\right)}
$$

Defining the particle terminal velocity by a force balance centred in a spherical particle dragged by air flux for stationary state, it comes:

$$
V_{T}=\sqrt{\frac{4 g d_{p}\left(\rho_{p}-\rho_{g}\right)}{3 \rho_{g} C_{d, s}}}
$$

$C_{d, s}$ is the drag coefficient for a single particle. Several relations are proposed to describe this coefficient in order to the flow regime (Kay and Nedderman, 1974; Klinzing, 1981; Clift et al., 1978). The one proposed by Kaskas (1964) (referred in Marcus et al., $1990)$ is explicit and valid for every regime:

$$
C_{d, s}=\frac{24}{R e_{t}}+\frac{4}{\sqrt{R e_{t}}}+0,4
$$

where $R e_{t}$ is the particle terminal Reynolds number and is defined by:

$$
\operatorname{Re}_{t}=\frac{\rho_{g} d_{p} V_{t}}{\mu_{g}}
$$

Some modifications must be added if a non-spherical particle is to be considered (PettitJohn and Chistiansen, referred in Klinzing, 1981 and equally suggested by Marcus et al., 1990).

For the drag coefficient, some correction must be added, as the particle is not isolated but immersed in the middle of others. Thus (Wen and Yu, 1960, cited in Klinzing, 1981):

$$
C_{d}=C_{d, s} \varepsilon^{-4,7}
$$

For a hydrodynamic description, a decaying constant $a$, must be defined. This parameter is intimately related to the mass transfer from core to annulus. A relationship is presented in the work of Bolton and Davidson (1998):

$$
k=\frac{0,1 \sqrt{\pi} U^{\prime}}{1+\frac{S t}{12}}
$$

with

$$
U^{\prime}=U_{0}\left(1-2,8 R e_{f}^{-1 / 8}\right)
$$

where $R e_{f}$, is the boiler Reynolds number, defined by

$$
R e_{f}=\frac{\rho_{g} D U_{0}}{\mu_{g}}
$$

and the Stokes number, St:

$$
S t=\frac{V_{t, \text { non-spherical }} U_{o}}{g D}
$$

Fan and Zhu (1998) proposed the following relation between $a$ and $k$ :

$$
a=\frac{4 k}{\left(\frac{U_{0}}{\varepsilon_{e}}-V_{t, \text { non-spherical }}\right) D}
$$


where $a$ is dependent of the vertical profile voidage, thus it is not really a constant but a function of height (Fan and Zhu 1998).

Another feature that is of great importance is the head loss along the bed. For most of the bed the headloss is the hydrostatic (Horio, 1997), plus a term referred to the particles acceleration, (Rhodes and Geldart, 1989):

$$
\begin{aligned}
& \Delta P=g \rho_{p}\left(1-\varepsilon_{e}\right) d h+g \rho_{g} \varepsilon_{e} d h \\
& \Delta P_{0}=\left(\rho_{p}-\rho_{g}\right)\left(1-\varepsilon_{o}\right) d h g+\frac{G^{2}}{\rho_{p}\left(1-\varepsilon_{o}\right)}
\end{aligned}
$$

$\Delta P$ stands for the head loss for a given height variation $d h, \Delta P_{o}$ the initial head loss, the head loss from the bottom to the beginning of the splash zone $\varepsilon_{0}$ the voidage of the bubbling bed. A comparative study is presented by Jonhsson and Leckner (1995) in figure 2:

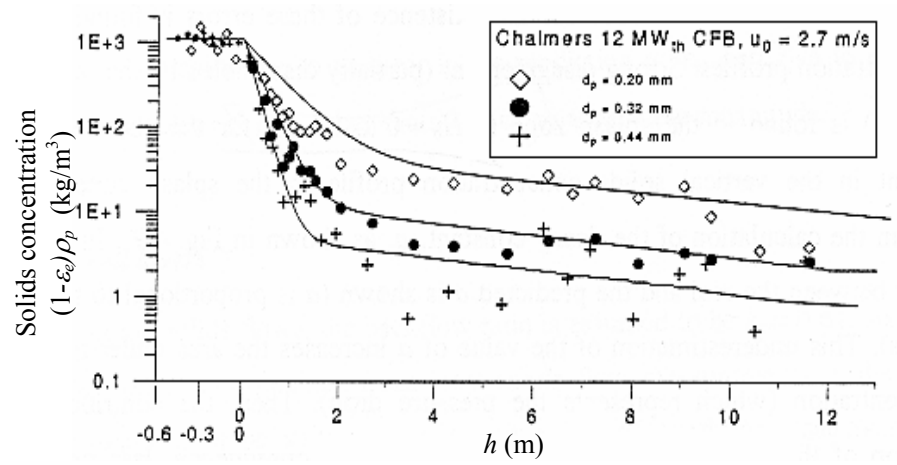

Figure 2: Vertical solids concentration profiles. Comparison with experimental results, Johnsson and Leckner (1995).

For a fully description of the hydrodynamic behaviour it is strictly necessary to describe the radial features of the bed: voidage, flow and velocity. Using laboratorial results, Patience and Chauoki (1995) (see Figure 3 a)) showed that the voidage radial profile only depends on its average value for the furnace cross section $\varepsilon_{s r}$, being independent of the flow regime, solids properties or bed dimensions.

$$
\varepsilon(\rho)=\varepsilon_{s r}^{0.4}-4 \rho^{6}\left(\varepsilon_{s r}^{0.4}-\varepsilon_{s r}\right)
$$
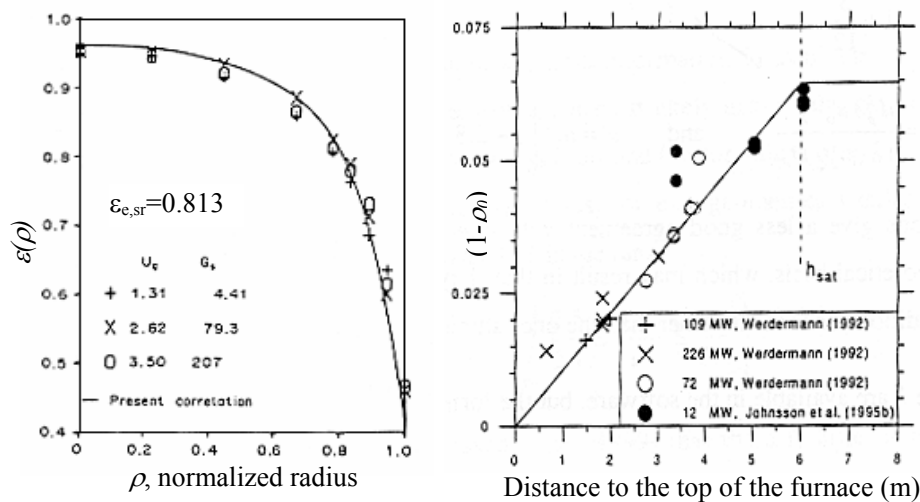

Figure 3 a) Voidage versus furnace normalised radius (Johnsson et al., 1995). b) Linear fitting for the annulus thickness. Chauoki and Patience (1995).

From the definition of average value, for cylindrical coordinates, one has for the nucleus voidage:

$$
\varepsilon_{n}=\left(1-\rho_{0}{ }^{6}\right) \varepsilon_{s r}{ }^{0.4}+\rho_{0}{ }^{6} \varepsilon_{s r}
$$

In the same way for the annulus voidage:

$$
\varepsilon_{a}=\left(1-\frac{\left(1-\rho_{0}^{8}\right)}{\left(1-\rho_{0}^{2}\right)}\right) \varepsilon_{s r}^{0,4}+\frac{\left(1-\rho_{0}^{8}\right)}{\left(1-\rho_{0}^{2}\right)} \varepsilon_{s r}
$$

According to Zhang et al. (1991), the annulus thickness seems to be independent of the solids flux and Johnsson et al. (1995) presented a linear regression and a saturation zone (see Figure 3 b)) according to their experimental data.

With the voidage profiles defined, it is possible to determine the main hydrodynamic entities to characterise the behaviour of the bed. The subsequent work refers to particles segregation (Jonhsson et al., 1995) or duct geometry problems (Kunii and Levenspiel, 1991), to name but a few.

When referring the heat transfer in $\mathrm{CFBB}$, there are many models concerning different types and sizes of boilers. A complete review can be consulted in Gelperin and Einstein (1971) for work done until 1970, later some new reviews from Botterill (1975), Xavier and Davidson (1984) and Baskakov (1984), the last being centred in bubbling bed results. A major part of the published data refers to small scale, laboratorial beds and are not useful for the present case of study. For industrial CFBB some data is published by Furchi et al. (1988), (see Figure 4), concerning the heat transfer coefficient (HTC) as the solids imposed flux varies for units using very small particles. Wu et al., (1987) review the data obtained by several authors for the correlation between HTC and particles concentration $\rho_{e}$ for several particle diameters $d_{p}$. Later Breitholz and Leckner (1997) presented important results for cold beds (see figure 5 a)). In the last few years, a lot of work has been done concerning circulating beds, (1996), Wu et al. (1989), Jestin et al. (1992). Breitholz et al. (2000) published the following results (Figures $5 \mathrm{~b}$ ) and $11 \mathrm{~b}$ )). Several authors present values of radiative and convective HTC's, treating them as additive and independent (Baskakov and Leckner, 1997, Grace et al., 1997, Breitholtz et al., 2000 , see figure 6 b)), although a complex coupling between both exists.

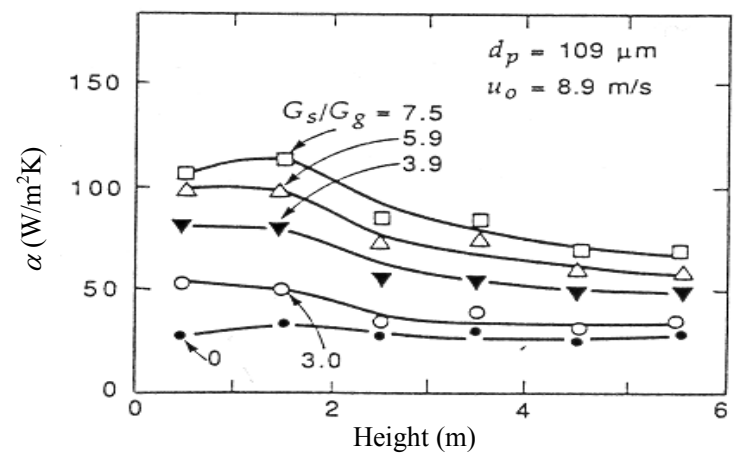

Figure 4: Heat transfer coefficient in vertical walls on a glass spheres bed of $7.2 \mathrm{~cm}$ of diameter.
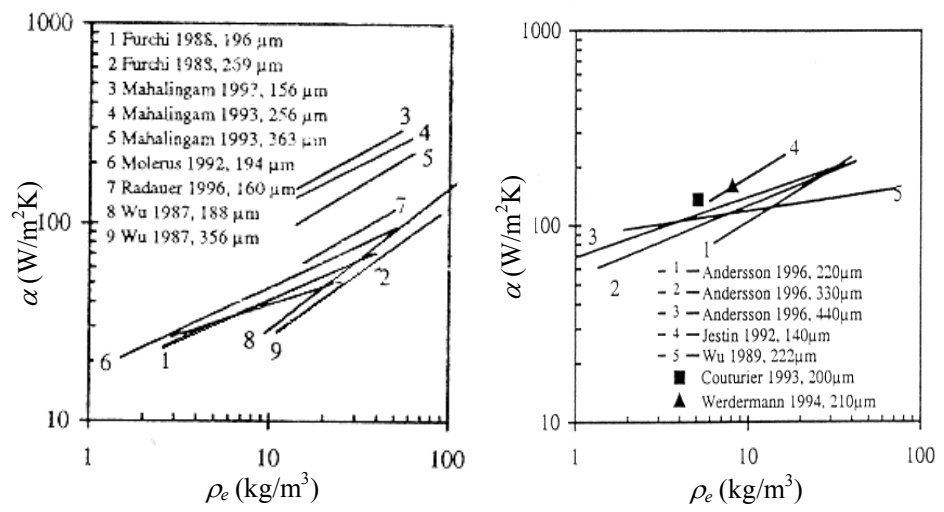

Figure 5 Heat transfer coefficients behaviour with particle concentration: a) The most important results for cold beds, Breitholz and Leckner (1997). b) Results for hot beds. All results except 2,3 and 4 are local values, the others are average ones, Breitholz et al. (2000). 

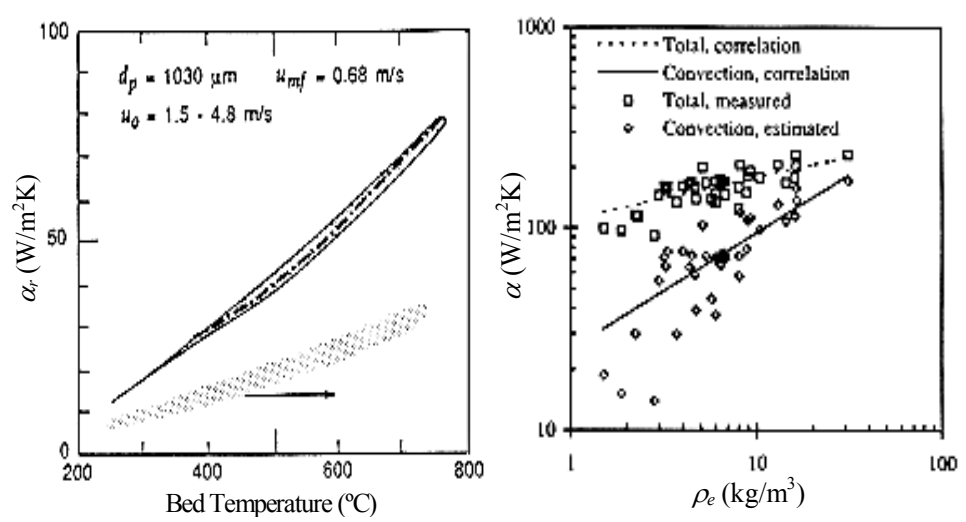

Figure 6: a) Radiative heat transfer coefficient (bed with glass spheres). Data from Ozkaynak et al (1983) adapted by Mathur and Saxena (1987). b) Comparison between total heat transfer coefficient and the convective one and subsequent correlations.

For the relation between the HTC and the bed temperature Ozkaynak et al. (1983) present some results (Figure 6 a)). Describing mathematically these heat transfer phenomena is the next step. Two major approaches can be found in the literature. One that considers the system as a biphasic flow and other that considers the particles immersed in a gas flow as an emulsion. The later approach will be described in detail, since it is the basis of the present work. Treating the particles and gas as an emulsion, requires the definition of some average properties. For the emulsion voidage $\varepsilon_{e}$, one has:

$$
\rho_{e}=\left(1-\varepsilon_{e}\right) \rho_{p}+\varepsilon_{e} \rho_{g}
$$

For the emulsion specific heat it is suggested that the definition of this quantity must be coupled with the emulsion voidage (Breitholtz and Leckner, 1997):

$$
\left\langle\rho c_{p}\right\rangle_{e}=\left(1-\varepsilon_{e}\right) c_{p, p} \rho_{p}+\varepsilon_{e} c_{p, g} \rho_{g}
$$

As for the thermal conductivity, the most used correlation was presented by Gelperin and Einstein (1971) based on data provided by Baskakov (1968):

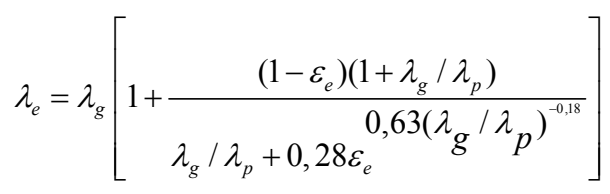

The mathematical explanation of the phenomenon is made both in an empirical and phenomenological ways. Again the radiative and convective HTC would be treated as additive. The radiative heat transfer was described as (Breitholtz and Leckner, 1997):

$$
\dot{Q}_{r}=\Sigma_{e f} \sigma\left(T_{1}^{4}-T_{2}^{4}\right) S
$$

where $T_{i}$ is the temperature of surface $i$ (either a physical surface or an imaginary one) and $\Sigma_{\text {ef }}$ the effective emissivity of the emulsion, given by (Breitholtz and Leckner, 1997):

$$
\Sigma_{e f}=\left(1 / \Sigma_{1}+1 / \Sigma_{2}-1\right)^{-1}
$$

As one of the radiative contributions is between emulsion and bed walls, an emulsion emissivity must be defined

$$
\Sigma_{e}=1-\left(1-\Sigma_{g}\right)\left(1-\Sigma_{e, p}\right)
$$

However since the behaviour of a particle among others is different than a single particle, Breitholtz (1996) suggests a new emissivity for the emulsion $\Sigma_{e, p}$ :

$$
\Sigma_{e, p}=\frac{2 \sqrt{\Sigma_{p}}\left(1-\exp \left(-\sqrt{\Sigma_{p}} 3 \frac{\left(1-\varepsilon_{e}\right)}{d_{p}} x\right)\right)}{1+\sqrt{\Sigma_{p}}+\left(1-\sqrt{\Sigma_{p}}\right) \exp \left(-\sqrt{\Sigma_{p}} 3 \frac{\left(1-\varepsilon_{e}\right)}{d_{p}} x\right)}
$$

where $x$ stands for the mean free path of the photon, described by Hotell and Sarofim (1967). For a given radiative element of volume $V$ and surrounding area $A$ :

$$
x=3,6 V / A
$$

According to the same authors, an alternative expression by Borodulya and Kovensky (1979) may be used:

$$
\Sigma_{e, p}=\Sigma_{p}^{0,38}
$$

The gas emissivity must account for the contribution of all the combustion gases and also soot (Taylor and Foster, 1975), although the main contribution is from carbon dioxide and water (Leckner, 1972). Another radiative energy term is that concerning the energy emitted by the core, which passes through the annulus and goes towards the wall. In consequence it is necessary to define a new parameter, the transmittance $\tau$, (Breitholtz and Leckner, 1997):

$$
\tau=\exp \left[-\left(\left(1+\Sigma_{p}\right) / 2\right)\left(3\left(1-\varepsilon_{e}\right) /\left(2 d_{p}\right)\right) x\right]
$$

The evaluation of the convective term is made after the definition of the convective heat transfer coefficient itself. The knowledge of the hydrodynamic of the biphasic flow, is not sufficient to solve the energy equation and several assumptions were made (Kudo et al., 1991); the most relevant is the fact that both gas and particles may be considered at the same temperature (Leckner, 1991). As the temperature of the annulus is less than the core temperature, it is expected that the combustion term should be negligible for the annulus (Breitholtz and Leckner, 1997). Once the predominant direction of the emuison flow is vertical one, the terms concerning other directions may be neglected. Thus, the energy equation becomes:

$$
\left\langle\rho c_{p}\right\rangle_{e} \frac{\partial T_{e}}{\partial t}=\lambda_{e} \frac{\partial^{2}}{\partial x^{2}} T_{e}
$$

Mahalingam and Kolar (1991) used the following boundary conditions:

$$
\begin{aligned}
& T=T_{e}, \text { para } t=0 \\
& T=T_{w}, \text { para } \mathrm{x}=0 \\
& T=T_{e}, \operatorname{para} \mathrm{x}=\phi
\end{aligned}
$$

$T_{e}$ stands for the annulus emulsion temperature, $T_{w}$ the wall temperature and $\phi$ is the annulus thickness. Therefore the solution appears as (Carslaw and Jaeger, 1959):

$$
\alpha_{c}(t)=\frac{\lambda_{e}}{\phi}\left(1+2 \sum_{i=1}^{\infty} \exp \left(-\frac{i^{2} \pi^{2} \lambda_{e} t}{\phi^{2}\left\langle\rho c_{p}\right\rangle_{e}}\right)\right)
$$




$$
\alpha_{c}(t)=\sqrt{\frac{\lambda_{e}\left\langle\rho c_{p}\right\rangle_{e}}{\pi t}}\left(1+2 \sum_{i=1}^{\infty} \exp \left(-\frac{i^{2} \phi^{2}\left\langle\rho c_{p}\right\rangle_{e}}{\lambda_{e} t}\right)\right)
$$

where $t$, is the duration of the contact between a pack of emulsion and the wall. As the results presented higher values than the empirical ones, it was suggested that a resistive term must be present (Breitholtz and Leckner, 1997). In fact a thin gas layer was detected next to the wall (Wirth, et al., 1991) and later Lints and Glicksmann (1993) proposed for the gas layer relative thickness:

$$
\delta=0,0282\left(1-\varepsilon_{e, s r}\right)^{-0,59}
$$

where $\varepsilon_{e, s r}$ is the average cross section voidage.

Finnaly the resistive term $\alpha_{c, w}$ is presented as (Breitholtz and Leckner, 1997):

$$
1 / \alpha_{c, w}=\delta d_{p} / \lambda_{g}
$$

and the overall convective HTC (Breitholtz and Leckner, 1997):

$$
\alpha_{c o n v}=\left(1 / \alpha_{c, w}+1 / \alpha_{c}\right)^{-1}
$$

The goal of the present work is to create a numerical procedure able to simulate a real CFBB, and, although much work has been done in such systems (Sinclair and Jackson, 1989; Ding and Gidaspow, 1990; Louge et al., 1991 , Alves et al., 2001; Alves and Mori, 1998; Alves and Mori, 1997;.Bolio et al., 1995; Tsuo and Gidaspow, 1990; Seu-Kim and Arastoopour, 1995), the present approach requires less calculation time, as it follows an integral procedure. Thus the simplicity of the model is of the essence.

The mathematical model: The system to model consists of a CFBB where the main hydrodynamic features are: the bubbling bed where the main part of combustion takes place (Adanez et al., 2000), the splash zone, a highly turbulent region above the bubbling bed providing a transition to the transport zone, and the transport zone itself, consisting in a core-annulus structure. The boiler has a square cross section, with refractory walls in the bubbling bed and part of the splash zone, and membrane walls thereafter. Heat transfer takes place towards these membrane walls.

The present work follows the models proposed by Rhodes and Geldart, (1987) continued by Bolton and Davidson (1988) and Horio et al. (1988), with the inclusion of the clusters. For the thermal analysis, the bed is treated as an emulsion following the expression presented earlier (Breitholtz and Leckner, 1997).

The key to solve this problem is to calculate temperatures for the core and annulus (for a given wall temperature). For simplicity purposes fundamental equations are solved using control volume analysis. Transversal sections of the bed with small heights are taken, one for the bubbling bed, another for the splash zone and several (about one hundred) to the transport zone divided in two cells, one for the core and other for the corresponding annulus. Mass and energy balances are made for each control volume, identifying each energy term and the connection between contiguous volumes is the basis for solving the equations.

To consider the biphasic flow as an emulsion some properties must be defined. For the emulsion emissivity and specific heat the work of Breitholtz and Leckner (1997) is followed (equations 25 and 29). The value of the gas specific heat may be taken from linear regression of tabled values. As for the emulsion thermal conductivity, the relation proposed by Gelperin and Einstein (1971) is used (equation 26)

Although the behaviour of the solids and gas flow may be perfectly treated as an emulsion, a clusters phase must be added in order to provide a better description of the physical phenomena (Horio et al. 1988). These clusters are groups of dozens of particles aggregated, with spherical form and dimensions of millimetres $(\mathrm{Li}$ et al., 1988; Horio and Kuroki, 1994). It is assumed that these structures preserve their characteristics, along their trajectory from the bubbling bed to the splash zone in a pseudo ballistic movement. It is assumed that the clusters voidage is equal to the bubbling bed one, i.e. the minimum fluidization voidage, and also that their inner temperature is very close to the one of the bubbling bed. Defining the properties of the cluster will be made by considering it as a element of the bed with different characteristic but with the same behaviour. For the cluster inner voidage $\varepsilon_{i, a g l}$, it comes directly from the definition that:

$$
\varepsilon_{i, a g l}=1-n_{p, a g l}\left(\frac{d_{p}}{d_{a g l}}\right)^{3}
$$

$d_{p}$ is the average particle diameter, $d_{a g l}$ is the average cluster diameter and $n_{p, a g l}$ the number of particles in the cluster. For the specific mass of the cluster $\rho_{a g l}$ :

$$
\rho_{a g l}=\left(1-\varepsilon_{i, a g l}\right) \rho_{p}+\varepsilon_{i, a g l} \rho_{g}
$$

where gas and particles specific masses take the corresponding bubbling bed values. In consequence, with the hydrodynamic knowledge of the cluster concentrations in the bed $C_{a g}$, it is possible to determine the cluster voidage in the bed:

$$
\varepsilon_{a g l}=\frac{C_{a g l}-\rho_{a g l}}{\rho_{g}-\rho_{a g l}}
$$

It is now possible to define a new bed voidage $\varepsilon$, counting with two "phases", a continuous one (the emulsion) and a discrete one (the clusters). It comes:

$$
\varepsilon=\left(1-\varepsilon_{a g l}\right) \varepsilon_{i, a g l}+\varepsilon_{a g l} \varepsilon_{e}
$$

For the new bed voidage, a new term (the cluster term) appears, $\left(1-\Sigma_{e, a g l}\right)$ (from the transmittances law, see equation 33):

$$
\Sigma_{e}=1-\left(1-\Sigma_{g}\right)\left(1-\Sigma_{e, p}\right)\left(1-\Sigma_{e, a g l}\right)
$$

where $\Sigma_{e, a g l}$ stands for the cluster emissivity in the middle of others, in the same way of the particles emissivity (35), it comes for a particle in the middle of others in the cluster:

$$
\Sigma_{a g l, p}=\frac{2 \sqrt{\Sigma_{p}}\left(1-\exp \left(-\sqrt{\Sigma_{p}} 3 \frac{\left(1-\varepsilon_{i, a g l}\right)}{d_{p}} x_{a g l}\right)\right)}{1+\sqrt{\Sigma_{p}}+\left(1-\sqrt{\Sigma_{p}}\right) \exp \left(-\sqrt{\Sigma_{p}} 3 \frac{\left(1-\varepsilon_{i, a g l}\right)}{d_{p}} x_{a g l}\right)}
$$

where $x_{a g l}=3,6 V_{a g l} / A_{a g l}=3,6 d_{a g l} / 6$

and $\quad \Sigma_{a g l}=1-\left(1-\Sigma_{g}\right)\left(1-\Sigma_{a g l, p}\right)$, 
however, the interaction with other clusters must be considered, thus for the cluster emissivity:

$$
\Sigma_{e, a g l}=\frac{2 \sqrt{\sum_{a g l}}\left(1-\exp \left(-\sqrt{\sum_{a g l}} 3 \frac{\left(1-\varepsilon_{a g l}\right)}{d_{a g l}} x\right)\right)}{1+\sqrt{\sum_{a g l}}+\left(1-\sqrt{\Sigma_{a g l}}\right) \exp \left(-\sqrt{\sum_{a g l}} 3 \frac{\left(1-\varepsilon_{a g l}\right)}{d_{a g l}} x\right)}
$$

Being the properties of the medium defined, the energy balance is made for each part of the bed. In bubbling bed the energy terms involved are: the energy associated to the in and outflow of emulsion; the energy transferred to the walls (although they are almost perfectly refractory) and finally the energy released by combustion that will be treated as a source term. Two types of flow must be considered, the emulsion phase and the bubble phase, thus a convective HTC towards the wall must account with the two contributions $\alpha_{l b, b}$, and $\alpha_{l b, e}$ (Kunii and Levenspiel, 1991):

$$
\alpha_{l b}=\delta_{b} \alpha_{l b, b}+\left(1-\delta_{b}\right) \alpha_{l b, e}
$$

where $\delta_{b}$ is the bubble fraction of the bed. When the bubble is in contact with the wall, two phenomena occur: radiation and convection. When the emulsion is in contact with the wall, three phenomena must be accounted for: convection, radiation and the term for the clusters (Kunii and Levenspiel, 1991). As particles attain quickly the wall temperature, the radiative term may be neglected, as well as the resistive term due to the thin gas layer adjacent to the wall. Thus Kunii and Levenspiel, (1991) propose:

$$
\alpha_{l b}=\delta_{b} \alpha_{r a d, b}+1,13\left[\lambda_{l b, e} \rho_{p}\left(1-\varepsilon_{m f}\right) c_{p, p} f_{b}\left(1-\delta_{b}\right)\right]^{1 / 2}
$$

$f_{b}$ stands for the bubble frequency near the wall and $\lambda_{l b, e}$ is the emulsion thermal conductibility. Assuming that the contact area between particles is very small it can be defined as follows (Kunii and Smith 1960):

$$
\lambda_{l b, e}=\varepsilon_{m f} \lambda_{l b, g}+\left(1-\varepsilon_{m f}\right) \lambda_{l b, p}\left(\frac{1}{\phi_{b}\left(\lambda_{l b, p} / \lambda_{l b, g}\right)+2 / 3}\right)
$$

$\phi_{b}$ stands for the equivalent gas film thickness around the contact points for the particles, Kunii and Levenspiel (1991),

$$
\varphi_{\mathrm{b}}=\frac{1}{3}\left(\lambda_{l b, p} / \lambda_{l b, g}\right)^{-0,2843}
$$

The emulsion radiative energy is evaluated in the classical way:

$$
\dot{Q}_{r, l b}=\Sigma_{e f} \sigma\left(T_{l b}^{4}-T_{w}^{4}\right) S
$$

with $\sigma$ being the Stefan-Boltzman constant, $T_{l b}$ the bubbling bed temperature and $T_{w}$ the wall temperature. The effective emissivity of the bubbling bed is defined through the emulsion and the bubbles emissivities.

Finally the energetic flow towards the walls becomes:

$$
\dot{Q}_{l b, w}=c_{w} \alpha_{l b} S\left(T_{l b}-T_{w}\right)
$$

where $c_{w}$ represents the percentage of energy that the refractory walls dissipate. This coefficient depends on the material and thickness and it is used by the boiler constructors (Andersson, 2000). Associated to the mass flow, there is an energetic flow, dependent of the gas and particles properties. Thus

$$
\begin{aligned}
& \dot{Q}_{g, e}=\dot{m}_{g} c_{p, g}\left(T_{g}-T_{r e f}\right) \\
& \dot{Q}_{p, e}=\dot{m}_{p} c_{p, p}\left(T_{p}-T_{r e f}\right)
\end{aligned}
$$

$\dot{m}_{g}$ and $\dot{m}_{p}$ represent the gas mass flow and the particles mass flow, respectively. $T_{g}$ is the temperature of the gas at the distributor and $T_{p}$ is the particles temperature at the entrance of the bubbling bed. Accordingly to the hydrodynamic model, there is an upward flow of emulsion that is dispersed into the splash zone, performing a pseudobalistic movement and descending mainly close to the walls (Kunni and Levenspiel, 1991). Therefore the energy balance for the bubbling bed takes into account two more terms,

$$
\dot{Q}_{e, s}=\dot{m}_{e, s} c_{p, e}\left(T_{l b}-T_{r e f}\right)
$$

where $\dot{m}_{e, s}$ is the mass flow of emulsion leaving the bubbling bed, $T_{l b}$ is the bubbling bed temperature, and

$$
\dot{Q}_{e, e}=\dot{m}_{e, e} c_{p, e}\left(T_{z e}-T_{r e f}\right)
$$

$\dot{m}_{e, e}$ is the mass flow of emulsion entering the bubbling bed from the splash zone, $T_{z e}$ is the corresponding temperature.

Finally the energetic term proceeding from the combustion must be considered. Although this contribution is a consequence of the bubbling temperature and vice-versa, it will be treated as a source term), and is calculated by other model (Adanez et al., 2000). Gathering all the energetic terms, the energy equation becomes:

$$
\dot{Q}_{g, e}+\dot{Q}_{p, e}+\dot{Q}_{e, e}+S T=\dot{Q}_{e, s}+\dot{Q}_{l b, w}
$$

This equation unknown variables are the bubbling bed and the splash zone temperatures.

The analysis of the energy balance of the splash zone will be presented after the analysis of transport zone. The transport zone has a core-annulus structure and the two regions in the zone will be treated separately although they present coupled terms. The transport zone will be divided in layers of small height, therefore the balance that will be present applies to each layer and the equations are generic.

For the core there are the entering and leaving emulsion mass flows in the vertical direction, the emulsion mass flow that leaves the core towards the annulus in the radial direction and the corresponding energy flows. The three mass flows can be determined from combining of equation (1) and the continuity equation. Thus:

$$
\begin{aligned}
& \dot{Q}_{e, i}=\dot{m}_{e, i} c_{p, e}\left(T_{c, i}-T_{r e f}\right) \\
& \dot{Q}_{e, s}=\dot{m}_{e, s} c_{p, e}\left(T_{c}-T_{r e f}\right) \\
& \dot{Q}_{e, c \rightarrow a}=\dot{m}_{e, c \rightarrow a l} c_{p, e}\left(T_{c}-T_{r e f}\right)
\end{aligned}
$$

where $T_{c, i}$ is the average temperature of the layer immediately under the layer in study and $T_{c}$ the average temperature of the immediately above layer. For temperatures about $800^{\circ} \mathrm{C}$, it is 
expected that the radiative heat transfer has an important role, thus a radiative term must be added:

$$
\dot{Q}_{r, c \rightarrow}=\Sigma_{e f, c} \sigma\left(T_{c}^{4}-T_{a}^{4}\right) S
$$

$T_{c}$ and $T_{a}$ are the core and annulus temperatures respectively. The effective emissivity is calculated as described earlier, and the photon mean free path calculated for the volume of the core cell (equations 32 and 33). As for the convective heat transfer, it will be neglected since the dominant movement from core to annulus concerns the mass flux towards the annulus (equation 63). Again the combustion term will be treated as a source term. Therefore, the energy balance for the core comes:

$$
\dot{Q}_{e, i}+S T=+\dot{Q}_{e, s}+\dot{Q}_{e, c \rightarrow a}+\dot{Q}_{r, c \rightarrow}
$$

The last equation depends on the core temperature and the temperature of the layer immediately beneath.

For the annulus cell, a colder emulsion downflow is present, in consequence the combustion term may be neglected as the combustion reaction is smothered (Kanury, 1977; Turns, 1996; Glassman, 1977). As for the mass transfer, there is a downward mass flow leaving the cell $\dot{m}_{e, i}$, another mass flow entering the cell from above $\dot{m}_{e, s}$, and the one coming from the core $\dot{m}_{e, c \rightarrow a}$ (eq. 66), thus the energetic terms are as follows:

$$
\begin{aligned}
& \dot{Q}_{e, s}=\dot{m}_{e, s} c_{p, e}\left(T_{a, s}-T_{r e f}\right) \\
& \dot{Q}_{e, i}=\dot{m}_{e, i} c_{p, e}\left(T_{a}-T_{r e f}\right)
\end{aligned}
$$

with $T_{a, s}$ as the temperature of the immediately above cell and $T_{a}$ the temperature of the cell in study. For the radiation from the core, two mechanisms may occur, either the annulus absorbs the radiation emitted from the core or it is transparent to it, and enables the radiation to be absorbed directly by the wall of the bed. The parameter that defines the proportion of this two phenomena is the transmittance $\tau$, (Breitholtz and Leckner 1997):

$$
\tau=\exp \left[-\left(\left(1+\Sigma_{p}\right) / 2\right)\left(3\left(1-\varepsilon_{e}\right) /\left(2 d_{p}\right)\right) x\right]
$$

As consequence the two energetic terms become:

$$
\dot{Q}_{r, c \rightarrow a}=(1-\tau) \dot{Q}_{r, c \rightarrow}
$$

for the energy that is absorbed by the annulus, and

$$
\dot{Q}_{r, c \rightarrow a}=\tau \cdot \dot{Q}_{r, c \rightarrow}
$$

for the energy that reaches the wall. As for the energy from the annulus towards the wall, convection and radiation will be treated as additive, thus

$$
\dot{Q}_{a, w}=\alpha_{c o n v, a} S\left(T_{a}-T_{w}\right)+\alpha_{r a d, a} S\left(T_{a}-T_{w}\right)
$$

where $T_{w}$ is the wall temperature, $S$ the contact surface (between annulus cell and wall) and $\alpha_{\text {conv, } a}$ and $\alpha_{\text {rad,a }}$ are the convective and radiative HTC's.

Taking all the terms, the energy equation becomes:

$$
\dot{Q}_{e, s}+\dot{Q}_{e, c \rightarrow a}+\dot{Q}_{r, c \rightarrow a}=\dot{Q}_{e, i}+\dot{Q}_{a, w}
$$

this equation depends on the annulus temperature and temperature of the cell immediately above the cell in study.

The most complex part of the bed is the splash zone, due to its intense turbulence and interactions, emulsion with upward and downward movement, clusters with upward and downward movement and clusters being destroyed by collisions (Kunii and Levenspiel 1991). This complexity cannot be modelled by a simple hydrodynamical model since there are no sufficient data to explain correctly the known features of the splash zone. In consequence the thermal model suffers by this lack of knowledge. The energetic flows in the splash zone are again due to mass transfer, radiative and convective towards the wall and combustion as a source term.

For the mass flow from the bubbling bed (vertical upward) and the mass flow from the splash zone towards the bubbling bed, one has respectively:

$$
\begin{aligned}
& \dot{Q}_{e, e}^{l b}=\dot{m}_{e, e}^{l b} c_{p, e}\left(T_{l b}-T_{r e f}\right) \\
& \dot{Q}_{e, s}^{l b}=\dot{m}_{e, s}^{l b} c_{p, e}\left(T_{z e}-T_{r e f}\right)
\end{aligned}
$$

These equations are the same as equations (58) and (59). For the interface between splash zone and the transport zone, again a vertical mass flow, mass coming from the transport zone $\dot{m}_{e, s}^{z t}$, and mass exiting the splash zone towards the transport zone $\dot{m}_{e, e}^{z t}$. For the energetic terms, it follows respectively:

$$
\begin{aligned}
& \dot{Q}_{e, e}^{z t}=\dot{m}_{e, e}^{z t} c_{p, e}\left(T_{z t}-T_{r e f}\right) \\
& \dot{Q}_{e, s}^{z e}=\dot{m}_{e, s}^{z e} c_{p, e}\left(T_{z e}-T_{r e f}\right)
\end{aligned}
$$

where $T_{z e}$ is the splash zone temperature and $T_{z t}$ the temperature of the lowest cell of the transport zone. Concerning the energy transferred towards the wall, many problems arise due to the lack of convective HTC data, thus it was chosen to model the splash zone as a transition between bubbling bed and transport zone and evaluate its HTC as a weighted average between the bubbling bed heat transfer coefficient, $\alpha_{c o n v, l b}$, and the transport zone one $\alpha_{c o n v, z t}$. The weight of each value $\left(b_{1}\right.$ and $\left.b_{2}\right)$ is determined by numerical experimentation. Hence the expression for the splash zone's convective HTC comes:

$$
\alpha_{c o n v, z e}=\frac{b_{1} \cdot \alpha_{c o n v, z t}+b_{2} \cdot \alpha_{c o n v, l b}}{b_{1}+b_{2}}
$$

As for the radiative transfer, it is calculated the same way as for the bubbling bed or the annulus in the transport zone. Finally the energy emitted towards the wall comes:

$$
\dot{Q}_{z e, w+}=\alpha_{c o n v, z e} S\left(T_{z e}-T_{w}\right)+\alpha_{r a d, z e} S\left(T_{z e}-T_{w}\right)
$$

The energy balance equation becomes:

$$
\dot{Q}_{e, e}^{l b}+\dot{Q}_{e, e}^{z t}+S T=\dot{Q}_{z e, w}+\dot{Q}_{e, s}^{l b}+\dot{Q}_{e, s}^{z e}
$$

The last equation depends on the splash one temperature and the temperature immediately above the splash zone.

The numerical procedure: The numerical procedure has two different purposes. First to simulate the thermal behaviour of a CFBB with different operating conditions or different physical 
characteristics and second to be a tool to debug problems with the descriptions of the physical phenomena described in the mathematical model. This procedure must mind two main requisites: to have a simple interface with external procedures in order to easily communicate with them and to have a small calculation time.

The language chosen to write the code was Matlab, its powerful graphic tools and the big routines library were the mains reasons to do so. The numerical procedure is organised in subroutines, each one referring to a different zone of the bed or numerical methods. Data interchange between submodels was made using text files.

This procedure leads with two kinds of physical variables; one kind refers to variables concerning "transfer" quantities, such as flows, velocities, heat coefficients that must be considered in the interfaces between the layers and the cells, those interfaces were numbered as $j$. The other kind concerns cells or layers properties, such as temperature, voidage, specific heat, etc. therefore two meshes were considered. For the second mesh, the properties were indexed to the cells in corresponding nodes, $i$.

The explanation of the equations to be solved leads to different problems for the transport zone, in order to solve the two coupled energy equations (for core and annulus), one has to deal with cells of different layers (see figure 7).

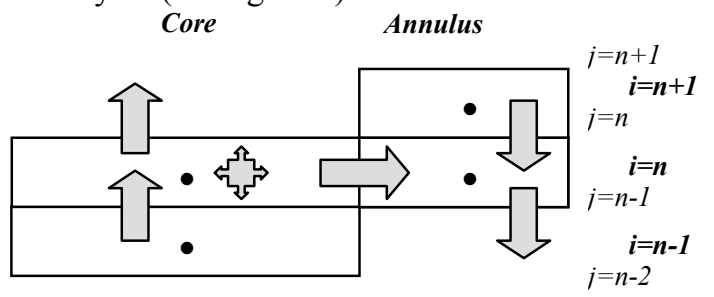

Figure 7: Intervenient cells for the resolutions of the energy equations in the $n$ layer of the transport zone.

The equations resolution was made using a root finding numerical procedure, such as Newton method, it had to be a simple still accurate method with few possibilities of divergence.

The procedure calculates the temperature of each zone, each layer of the transport zone, and each cell of the layers. In consequence, it calculates the HTC's and the energy terms in the equations. It also evaluates the numerical uncertainty of the procedure by applying the energy balance to the whole system. Starting with the procedure needs an initial bubbling bed temperature since the poor modelling of the splash zone does not provide enough equation to solve all the parameters. Still, because the physical system is closed (riser, cyclone and downcomer), the numerical procedure simulates this behaviour and iterates the overall procedure in order to adjust the initial guess for the bubbling bed temperature.

Some results: The subsequent study case presents typical hydrodynamic values for the following physical features.

Geometrical features of the system

\begin{tabular}{|l|l|l|}
\hline Boiler's height & $13.5[\mathrm{~m}]$ \\
\hline $\begin{array}{l}\text { Height for the exit duct } \\
\text { towards the cyclone }\end{array}$ & $10.95[\mathrm{~m}]$ \\
\hline $\begin{array}{l}\text { Height for the secondary } \\
\text { air input }\end{array}$ & $2.10[\mathrm{~m}]$ \\
\hline Height for the mass input & $2.00[\mathrm{~m}]$ \\
\hline $\begin{array}{l}\text { Height of the refractory } \\
\text { walls }\end{array}$ & $2.20[\mathrm{~m}]$ & \multicolumn{2}{|l|}{} \\
\hline & $\begin{array}{l}\text { Refractory } \\
\text { walls }\end{array}$ & $\begin{array}{l}\text { Non-Refractory } \\
\text { walls }\end{array}$ \\
\hline Dimensions & $1.42 \times 1.42[\mathrm{~m}]$ & $1.46 \times 1.66[\mathrm{~m}]$ \\
\hline $\begin{array}{l}\text { Cross section for the } \\
\text { cyclone entrance }\end{array}$ & $1.02\left[\mathrm{~m}^{2}\right] \quad(0.6 \times 1.7)$ \\
\hline
\end{tabular}

\begin{tabular}{|l|l|}
\hline Wall tubes diameter & $0.0603[\mathrm{~m}]$ \\
\hline Fins width & $0.00880[\mathrm{~m}]$ \\
\hline $\begin{array}{l}\text { Number of tubes per } \\
\text { membrane wall }\end{array}$ & $21[-]$ \\
\hline
\end{tabular}

Fluidization particles average properties.

\begin{tabular}{|l|l|}
\hline Particle average diameter & $393 \times 10^{-6}[\mathrm{~m}]$ \\
\hline Particle average specific mass & $2600\left[\mathrm{~kg} / \mathrm{m}^{3}\right]$ \\
\hline Particles average sphericity & $0.83[-]$ \\
\hline
\end{tabular}

Operating conditions (Tella and Johnsson, 2000).

\begin{tabular}{|l|l|}
\hline Air velocity for primary input. & $3.4[\mathrm{~m} / \mathrm{s}]$ \\
\hline Air Excess & $29 \%$ \\
\hline Bubbling bed's height & $0.29[\mathrm{~m}]$ \\
\hline Splash zone's height & $3.23[\mathrm{~m}]$ \\
\hline
\end{tabular}

Thermal characteristics of the system.

\begin{tabular}{|l|l|}
\hline Input air temperature & $473.15[\mathrm{~K}]$ \\
\hline Membrane wall temperature & $440.0[\mathrm{~K}]$ \\
\hline Reference temperature & $273.15[\mathrm{~K}]$ \\
\hline Refractory walls losses & $10 \%$ \\
\hline
\end{tabular}

\section{The hydrodynamic behaviour:}

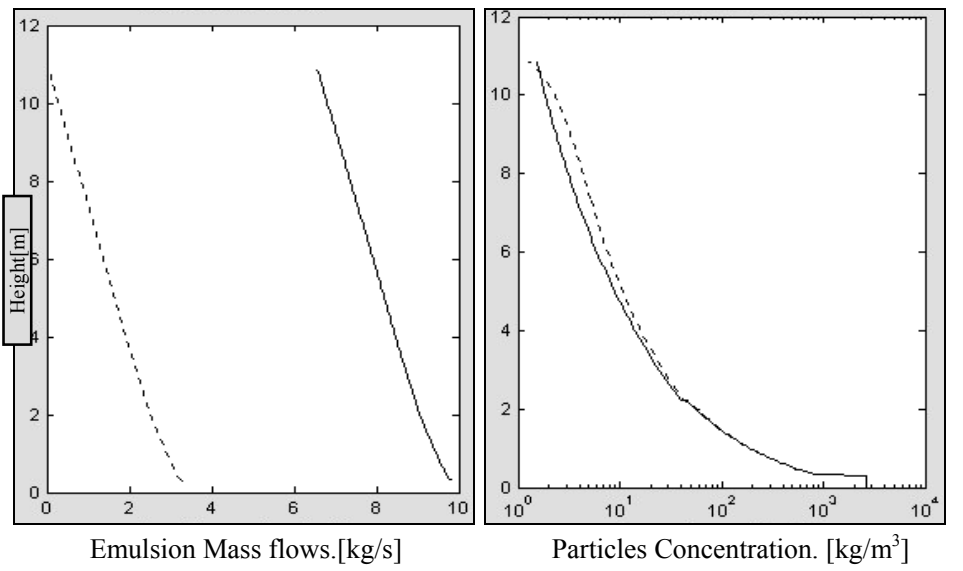

Figure 8: a) Emulsion mass flow with height: --- Annulus; - Core. (Tella and Johnsson, 2000). b) Particle concentration with height: --- Annulus; — Core. (Tella and Johnsson, 2000).

Analysing the previous figures, one can conclude that the mass transfer from core to annulus is constant along the bed. This

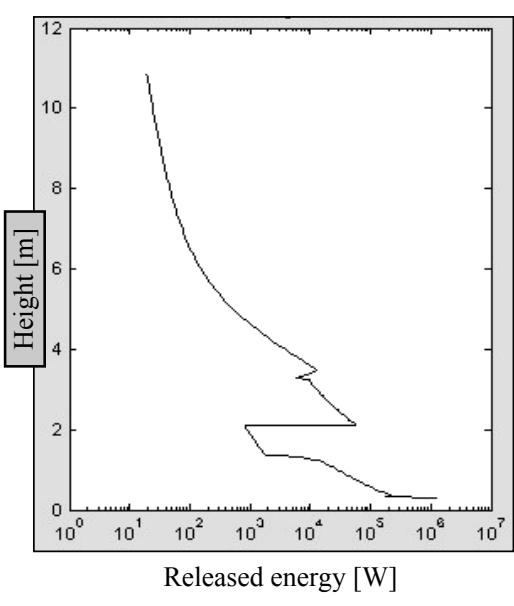
for itself constitutes a problem, since it should not happen and it will raise problems as it will be seen later.

One of the main features of the CFFB is well explicit in the figure $8 \mathrm{~b}$ ) its core-annulus structure for the for the transport zone. Consequence of the lesser concentration for the upper parts of the transport zone, the difference between core and annulus becomes again negligible.

Figure 9: Heat release by combustion with height. Adanez et al. (2000) 


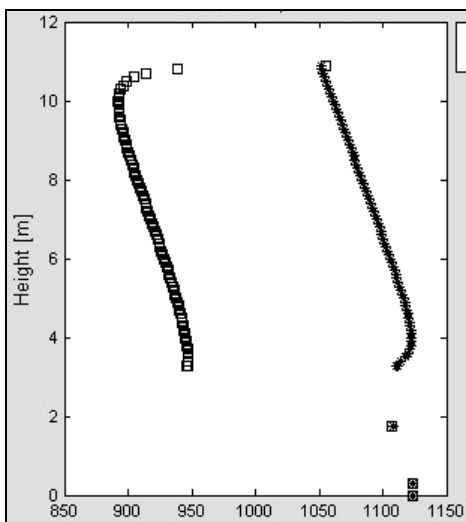

Heat transfer coefficients $\left[\mathrm{W} / \mathrm{m}^{2} . \mathrm{K}\right]$

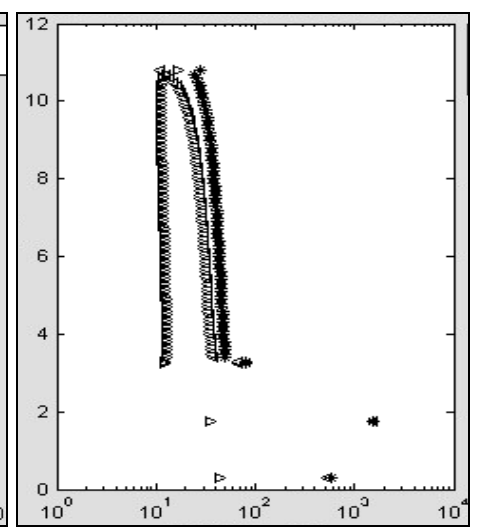

Heat transfer coefficients $\left[\mathrm{W} / \mathrm{m}^{2} . \mathrm{K}\right]$
Figure 10: a) Temperature profiles: * Core; $\square$ Annulus. b) Heat transfer coefficients from bed towards the walls. * Total HTC; $\triangleleft$ convective HTC; $\triangleright$ radiative HTC.

The heat release shown in the figure 9 represents the energy release by combustion. It is easy to understand that most of the combustion takes place in the bubbling bed and that there is a new peak near the secondary air injection. Based on this data and operating conditions, the thermal model was run and its results are presented in the form of temperature and HTC's.

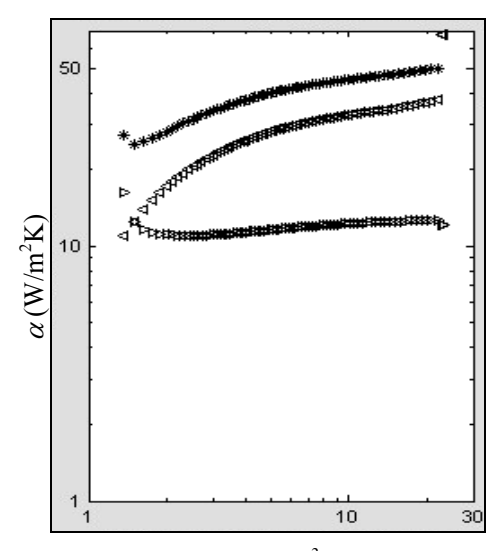

$\rho_{e}\left(\mathrm{~kg} / \mathrm{m}^{3}\right)$

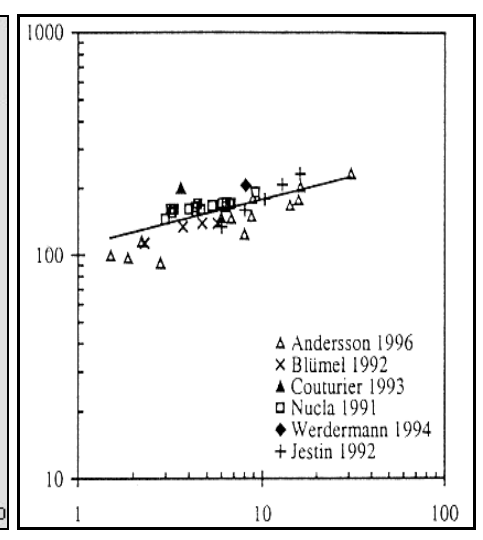

$\rho_{e}\left(\mathrm{~kg} / \mathrm{m}^{3}\right)$
Figure 11 a) Heat transfer coefficients behaviour with the particles concentration for the annulus. * Total HTC; $\triangleleft$ convective HTC; $\triangleright$ radiative HTC. b) Experimental results for the behaviour of heat transfer coefficients with the particles concentration Breitholz, Leckner and Baskakov. (2000).

Power transferred towards the walls.

\begin{tabular}{|c|c|c|c|c|}
\hline \multicolumn{4}{|c|}{ Total power towards the walls } & $7.28[\mathrm{MW}]$ \\
\hline \multicolumn{4}{|c|}{$\begin{array}{l}\text { Ratio between heat released by combustion and } \\
\text { heat transferred toward the walls. }\end{array}$} & $78.2 \%$ \\
\hline \multicolumn{4}{|c|}{ Energetic flow towards the cyclone } & $3.64[\mathrm{MW}]$ \\
\hline \multicolumn{5}{|c|}{ Numerical Uncertainty: $0.204 \%$} \\
\hline & \multicolumn{2}{|c|}{$\begin{array}{c}\text { Total power towards } \\
\text { the refractory walls } \\
{[\mathrm{MW}] /[\%]}\end{array}$} & \multicolumn{2}{|c|}{$\begin{array}{l}\text { Total power towards } \\
\text { the non-refractory } \\
\text { walls }[\mathrm{MW}] /[\%]\end{array}$} \\
\hline Bubbling Bed & 0.0667 & 0.717 & --- & --- \\
\hline Splash Zone & 0.0460 & 0.494 & 6.48 & 69.7 \\
\hline Transport Zone & --- & --- & 0.681 & 7.32 \\
\hline \multirow[t]{2}{*}{ Subtotals } & 0.113 & 1.21 & 7.16 & 77.0 \\
\hline & \multicolumn{2}{|c|}{ Total } & 7.27 & 78.2 \\
\hline
\end{tabular}

Discussion: Figure 10 a) presents a linear evolution for the both for core and annulus temperatures in the transport zone with a slight warming in the bottom zone, the core cools down about $75 \mathrm{~K}$, showing an almost constant temperature profile. The annulus, being $175 \mathrm{~K}$ colder, shows the same trend. On the other end, core and annulus temperature get closer towards the furnace top. The small warming of the core, when compared with experimental trends, may be in some way a readjustment of the model to the poor modelling of the splash zone. However the splash zone shows a homogeneous temperature for both core and annulus, revealing the expected high mixture between upward and downward flows.

The heat transfer coefficient behaviour shown in the figure 10 b) is almoust linear, around $40 \mathrm{~W} / \mathrm{m}^{2} \mathrm{~K}$. A small increase at the top of the furnace is due to the significant enlarge of the radiative heat transfer coefficient in consequence of the rise of the annulus temperature. Another reflex of the imperfect mathematical model of the splash zone are the high values of the HTC at the bottom of the splash zone. These values are the result of the numerical adjustment made in order to achieve a reasonable temperature profile along the furnace height and therefore do not have a proper physical meaning. As can be seen by figure $10 \mathrm{~b}$ ), at the top of the furnace the radiative coefficient turns dominant due to the increase of the temperature and by the decrease of the convective coefficient as consequence of the decrease of the emulsion concentration.

With an almost linear behaviour, along the furnace, the HTC's profiles take values lower than the experimental results, Andersson (1996) (see Figure 10 b). Numerical data are in the range of 60 to $110 \mathrm{~W} /\left(\mathrm{m}^{2} \mathrm{~K}\right)$ for solids concentrations varying between 1 and $30 \mathrm{~kg} / \mathrm{m}^{3}$. Only for higher solid concentrations (20 $\mathrm{kg} / \mathrm{m}^{3}$ ) numerical results get closer to experimental ones.

The value of the energetic efficiency is a very reasonable one (Andersson, 2001) 77\%, the rest of the energy is directed towards the cyclone where it can be still utilised. For this type of furnaces, volatiles combustion inside the cyclone is of great importance.

The small concordance of some of the numerical results compared with experimental data is mainly due to the reduced knowledge of the phenomena occurring in the splash zone, either thermal or hydrodynamic. The lack of empirical values and models that predict and explain the interaction between emulsion and clusters in this incipient core-annulus region is of essence to achieve a fair thermal model for a CFBB.

The presented work aimed to build a numerical tool that would simulate the thermal behaviour of a CFBB. It recreates some known and important features and deals with the unknown CFBB characteristics in a way that enables the numerical procedure to achieve its main purpose, although at the expense of some strange results in the splash zone heat transfer modelling.

\section{References:}

Adanez, J., de Diego, L., García-Labiano, F., "Process Simulation of Circulating Fluidized Beds with Combustion/Gasification of Biomass - Progress Report", JOR3CT980306, (2000).

Alves, J. and Mori, M., $18^{\circ}$ Congresso Ibero Latino-Americano de Métodos Computacionais para Engenharia, Vol. 4, pp. 1789-1796, (1997).

Alves, J. and Mori, M., Computers Chem. Eng., Vol. 22, Supl., pp. S763-S766, (1998). Alves, J., Martignomi, W., Mori, M., J. Braz., Soc. Mechanical Sciences, Vol. 23, No 1 , pp. 91-104, (2001)

Andersson, B.-Å., Personal communication, (2000), Göteborg, Sweden.

Andersson, B.-Å., Personal communication, (2001), Göteborg, Sweden.

Baskakov, A. and Leckner, B., Powder Technology, Vol. 90, pp. 213-218, (1997).

Berruti, F., Chaouki, J., Godfroy, L. Pugsley, T., Patience, G., The Canadian Journal of Chemical Engineering, Vol. 73, pp 579-602, (1995).

Bolio, E., Yasuna, J. and Sinclair, J., AIchE J., Vol. 41, No 6, pp. 1375-1388, (1995).

Bolton, L. and Davidson, J., "Circulating Fluidized Bed Technology II" (eds. P. Basu and J. F. Large), Pergamon Press, pp. 139-146, (1998).

Borodulya, V., and Kovensky, V., "Heat and Mass Transfer: Physical Foundations and Methods" ITMO AN BSSR, Minsk, pp. 31-34, (1979).

Botterill, J., "Fluid-Bed Heat Transfer" Academic Press, New York, (1975)

Breitholtz, C, Leckner, B. and Baskakov, A, III European Conference on Fluidization, Toulouse, França, (2000).

Breitholtz, C. and Leckner, B., Trends in Heat, Mass and Momentum Transfer, Vol. 3, pp. 85-104, (1997).

Breitholtz, C., Ph D. Thesis, Chalmers University of Technology, Göteborg, Sweden, (2000).

Breitholtz, C., Degree Thesis, Chalmers University Technology, Göteborg, Sweden, (1996).

Breitholz, C. and Leckner, B., $4^{\text {th }}$ Minsk International Heat and Mass Transfer Forum, Minsk, (2000). 
Carlsaw, H. and Jaeger, J., "Conduction of Heat in Solids", Oxford University Press, London, (1959)

Chen, C. C. and Chen, C. L., Chem. Eng. Sci., vol. 47, pp. 1017-1075, (1992).

Clift, R., Grace, J. and Weber, M., "Bubbles, Drops and Particles", Academic Press, New York, (1978).

Darton, R. C., LaNauze. R. D., Davidson, J. F., Harrison, D., Trans. I ChemE, Vol. 55, pp. 274-280, (1977).

Ding, J. and Gidaspow, D., AIChE J., Vol. 36, № 4, pp. 523-538, (1990).

Fan and Zhu, "Principles of Gas-Solid Flows", Cambridge University Press, (1998).

Furchi, J., Goldstein, L., Lombardi, G., and Mohseni, M., "Circulating fluidized bed Technology II” (Eds. P. Basu and J. F. Large), Pergamon Press, Oxford, (1988).

Geldart, D., and Abrahamsen, A., Chem. Eng. Prog. Symp. Ser. Vol. 77, No 205, 160 (1981).

Gelperin, N. and Einstein, V., "Fluidization" (Eds. Davidson and Harrison), Academic Press, New York, (1971).

Glassman, I., "Combustion", Academic Press, New York, (1977).

Grace, J., Avidan, A., Knowlton, T.,. "Circulating Fluidized Beds", Blackie Academic \& Professional, (1997).

Horio, M. and Kuroki, H., Chem. Eng. Sci, Vol. 49, 2413, (1994)

Horio, M., "Hydrodinamics" em "Circulating Fluidized Beds", (eds. Grace, J., Avidan, A., Knowlton, T.), Blackie Academic \& Professional, (1997).

Horio, M., Morishita, K. Tachibana, O. and Murata, N., "Circulating fluidized bed Technology II" (eds. P. Basu and J. F. Large), Pergamon Press, Oxford, pp. 147-154, (1988).

Hotell, H. and Sarofim, A., "Radiative Transfer", McGraw-Hill Book Company, New York, (1967).

Jestin, L., Meyer, P., Schmitt, G. and Morin, J. "Transfer de chaleur dans le foyer du lit fluidise circulante de 125 MW de Carlin", Electricite de France, Saint Denis, (1992).

Johnsson, F., Zhang, W., and Leckner, B., Proc. $2^{\text {nd }}$ Int. Conf. on Multiphase Flow, (eds. Serizawa, Fukano and Bataille) Kyoto, (1995).

Jonhsson, F. and Leckner, B., $13^{\text {th }}$ International Conference on Fluidized Bed Combustion, Orlando, (1995).

Kanury, A., "Introduction to Combustion Phenomena", Gordon and Breach Science Publishers, New York, (1977).

Kaskas, (1964) em Rizk, F., "Chapter 10 - Principles of Pneumatic Conveying. Encyclopedia of Fluid Mechanics. Vol. 4. Solids and Gas Solids Flows", (Ed. N. P. Cheremisinoff), Gulf Publishing Company, (1986).

Kay and Nedderman, "An Introduction To Fluid Mechanics and Heat Transfer", $3^{\circ}$ Edição, Cambridge University Press, (1974).

Klinzing, G., "Gas-Solid Transport”, McGraw-Hill Book Company (1981)

Kudo, K., Tanicuchi, H., Kaneda, H., Yang, W.-J., Zhang, Y.-Z., Guo and Matsumara, "CFB Technology III" (Eds. P. Basu., M. Horio and M. Hasanbati), Pergamon Press, Oxford, pp. 269-274, (1991).

Kunii, D. and Levenspiel, O. "Fluidization Engineering", Butterworth-Heinemann, (1991).

Kunii, D. and Levenspiel, O., "Fluidization Engineering", Wiley, New York, (1969).

Leckner, B., "CFB Technology III” (eds. P. Basu., M. Horio and M. Hasanbati), Pergamon Press, Oxford, pp. 27-37, (1991).

Leckner, B., Combustion and Flame, Vol. 19, 33 (1972)

Leckner, B., Golriz, M., Zhang, W. and Anderson, B.-Å., Proceedings $11^{\text {th }}$ International Conference on Fluidized Bed Combustion, Vol. 2, pp. 771-776, (1991).

Li, J., Li, Y. and Kwauk, M., "Circulating fluidized bed Technology II" (eds. P. Basu and J. F. Large), Pergamon Press, Toronto, (1998).

Lints, M. and Glicksmann, L., AIChE Symposium Series, Vol. 89 ( $\mathrm{N}^{\circ}$ 296), pp. 35-47, (1993).

Lints, M., Ph. D. Thesis, Massachusetts Institute of Technology, Cambridge MA, (1992).

Louge, M., Lisher, J. and Chang, H., Powder Technology, Vol. 62, pp. 269-276, (1990).

Louge, M., Mastorakos, E. and Jenkins, J. J. Fluid. Mech., Vol. 231, pp. 345-359, (1991)

Lyngflet, A., Åmand, L.-E. and Leckner, B., Fuel 11(8/9), pp. 953-959, (1998).

Mahalingam, M. and Kolar, A., AIChE J. Vol. 37, 1139, (1991).

Maliska, C., "Transferência de Calor and Mecânica dos Fluidos Computacional: Fundamentos, Coordenadas Generalizadas", LTC Editora, Brasil, (1995).

Mathur, A. and Saxena, S., AIChE J., Vol. 33, 1124, (1987).

Ozkaynak, J., and Frakenfield, T. em "Fluidização IV", 371, (Eds. D. Kunii and R. Toei), Engineering Foundation, New York, (1983).

Patankar, S., "Numerical Heat Transfer and Fluid Flow", Hemisphere Publishing Corporation, Washington, (1980);

Patience, G. S. and Chauoki, J., Preprints Fluidization VIII, Tours, pp. 33-40, (1995).

Rhodes, M. and Geldart, D., Chem, Eng. Res. Des., Vol. 67, pp. 20-29, (1989).

Rhodes, M., and Geldart, D., Powder Technology, Vol. 53, 115, (1987)

Rhodes, M., Eng. Res. Des., Vol. 67, pp. 30-37, (1989).

Seu-Kim, H. and Arastoopour, H., The Canadian Journal of Chemical Engineering, Vol. 73, pp. 603-611, (1995).

Sinclair, J. and Jackson, R., AIChE J., Vol. 35, No 9, pp. 1473-1486, (1989)

Taylor, P.B. and Foster, P.J., Int. J. Heat Mass Transfer, Vol. 18, pp 1331-1332, (1975)

Tella, D. and Johnsson, F., "Hydrodynamics of a Circulating Fluidized Bed Furnace -

Progress Report", JOR3CT980306, (2000).

Tsuo, Y. and Gidaspow, D., AIChE J. Vol. 36, No 6, pp. 885-896, (1990).

Turns, S. R., "An Introduction to Combustion, Concepts and Applications", McGraw-Hill International Editions New York, (1996).

Wen, C. Y. and Chen, L. H., AIChEJ, Vol. 28, 117, (1982).

Wen, C. Y. and Yu, Y. H., Chem. Eng. Progr. Symp. Series, Vol. 62, pp. 110-111, (1960) citado por G. E. Klinzing, Gas-Solid Transport. McGraw-Hill Book Company (1981).

Wu, R., Grace, J., Lim, C. and Brereton, C., AIChE J., Vol. 35, 1685, (1989).

Wu, R., Lim, C., Chouki, J. and Grace, J., A.I.Ch.E.J., Vol. 33, 11, (1987).

Xavier, A. and Davidson, J., "Fluidization"(Eds. J.F. Davidson), Academic Press New

York, (1984).

Zhang, W., Tung, Y., and Jonhsson, F. Chem. Eng, Sci. Vol. 46, 3045, (1991). 